\title{
Research on Endowment Rural Only Child
}

\author{
Cui Rui ${ }^{1}$, Yu Jiani ${ }^{1} \&$ Zhu Yuxia ${ }^{1}$ \\ ${ }^{1}$ School of Management, Shanghai University of Engineering Science, Shanghai, China \\ Correspondence: Cui Rui, School of Management, Shanghai University of Engineering Science, Long Teng Road No. \\ 333, China. Tel: 86-136-8177-4136. E-mail: 100158183@qq.com
}

Received: October 6, 2014 Accepted: November 7, 2014 Online Published: January 10, 2015

doi:10.5430/sass.v2n1p19 URL: http://dx.doi.org/10.5430/sass.v2n1p19

This project is sponsored by Shanghai University of Engineering Science Innovation Fund for Graduate Students (No. E1-0903-14-01054)

\begin{abstract}
Family planning for 30 years, China produced a huge number of only child groups, and the first generation of only children of their parents, about to enter old age. Reverse pyramid's only child family more prone to pension risks, especially in rural areas, family size, traditional family pension function gradually weakened, and some congenital vulnerable child families, making life care and spiritual endowment involved consolation seemed powerless. In this paper, a comprehensive study by the current existing pension issues.
\end{abstract}

Keywords: only child, pension contents, pension risk

\section{Introduction}

Family planning for 30 years, the Chinese have fewer over 400 million people, excessive growth of population has been effectively controlled, but at the same time also produced hundreds of millions of only children. Most of the first generation of only children now married, and their parents have entered or are about to enter the ranks of the elderly aging population. According to the National Bureau of Statistics in 2010 the sixth census data, the population in China and nearly 178 million over 60 years, 65 years and over population close to 119 million compared with the " the fifth population census ", the proportion increased by $2.93 \%$ and $1.91 \%$, to $13.26 \%$ and $8.87 \%$, and a higher degree of aging in rural areas. Many researchers pointed out that only child family "reverse pyramid" type than non-child families face more risk because if one child disability or death occurs, then his family will face difficulties in pension and other issues. In addition, the only child family married, usually form a "4-2-1" family structure, or even a "8-4-2-1" family structure, pension burden is very heavy. And only child family family is the "empty nest" families of high-fat group, because the one child, in order to work and other factors that forced them to leave their parents. In the majority of the Chinese population in rural areas, according to the survey, the number has more than 30 million only child family. Such a largeonly child family population, family supporting problem must pay attention to.

Beginning in 2004, the government Implementation family planning on the part of the system for rewarding and supporting rural trial, from the national level to open up part of the family planning Social Security precedent. In recent years, China's rural situation has undergone great changes, including the plight of the outflow of labor, peasant doctor, pension and other aspects that have made national policy related to constantly adjust.The sixteen session of the six plenary session of the Central Committee and the next session that "the establishment of a social security system covering urban and rural residents," the goals and tasks, the level of social security in rural areas is gradually improving, but this is an inclusive rural masses pension system for in China for all the family, for the protection of all households are the same.

Only child family as a case of an exception, did not enjoy benefits such as its contribution to the state in the process of policy formulation is not reflected in its particularity.In this universal system so that only child family parents creatively incorporated into the overall pension framework of national social security system in rural areas, so that they could enjoy the ordinary elderly pension benefits, but also as a special population groups get a reasonable 
discount and compensation, need to go through the relevant feasibility studies, carried out in an appropriate manner to complement their supporting problems

\section{Literature Review}

By reading the relevant literature, found that due to the family planning policy in foreign rare, there is little research in this area, so the main access to research literature scholars and relevant national policy documents. China's family planning policy proposed from the beginning, some experts and scholars aware of some of the issues will have pensions, but the pension problem only child family have some time buffer, before the 1990s, almost did not get a response. Since 2000, academia and government pension problems in rural only child family more and more attention, many researchers are on China's only child problems were studied, such as Zhou De-lu through rural Shandong survey indicated only child family in rural areas in pension the weak position and put forward relevant countermeasures. On the basis of previous studies Wu Pei-fen put forward pension plight of the aging population trend of China's only child families in rural areas and countermeasures. Zhou ChangHong, Liu Song, who based five counties nationwide survey study of rural elderly parents-child family structure and characteristics of the empty nest.

But, these studies did not involve only child families in rural areas in poor mountainous areas, this article selected rural only child as the object of study, study pension issues their rural only child families.

\section{The Heavy Burden of the Only Child Family Pension}

This model family pension in the history of China have maintained quite a long time success, but the success of this model is the economic basis of its history. Twenty-thousand-year feudal societyChina has always been self-sufficient peasant economy, commodity circulation developed, exchanged frequent population movements, the land is the economic foundation of rural life. And the whole land is to maintain family ties, which serves as a major means of production, is the source of most of the people living life, especially in old age, the material basis for both land endowment, but also on the objective to ensure that the manpower required pension resources. But with the existence of a market economy and binary structure between urban and rural areas, such as shackles, and now the land endowment function gradually weakened, because the land revenue has been insufficient to ensure the survival and development of the entire family and pension needs of traditional land endowment function is weakening.

When most of our rural family planning policy implemented, positive response to the national policy, reducing the excessive growth of the population. But as time goes on, the problem of controlling population growth above, also produced some new problems, which produce a lot of only child families. With the only child family parents age, children increasingly heavy pension burden, the most direct manifestation of the economic burden and less pension required human resources. Nowadays, many young workers forced to live in the village had to go out to work pressure, and once the children go, at home, it is likely that only the "empty nest elderly" for the elderly. "empty nest elderly" lack of care for the elderly in rural areas, the traditional filial piety and other Chinese civilization are due to objective reasons, can't implemented.

\subsection{The Classification of the Only Child Family Supporting Pension Content}

About Pension content. There are different from different perspectives different interpretations, but in the context of the traditional family pension, pension summarized the contents of the general economic support, life care and spiritual solace in three aspects. Taking into account the reality in rural areas, dominated by the family pension, so the following will be economic support and spiritual solace rural only child family supporting problem( pension two aspects to elaborate.

1) Economic support is not the greatest difficulty

Development of industrialization makes a lot of the rural population to urban, original women bear the primary care obligations also began traveling to work increased "emptynest elderly " for the elderly, which not only take care of the elderly potentially reduced resources, but also it lost on family resources and family the right to control the main income persons. Endowment support the existence of difficulties in the economy, but on the whole, the economic factor is the rural family supporting

2) Problem pension is still the greatest difficulty

First, from a policy perspective the country concerned, since 2004, the government has in some rural pilot of only child families reward grants.If old Solitary People add the child's maintenance costs, the rural elderly can still rely on 
55 yuan pension, their livelihoods. In the country as a whole, the current model of rural old-age insurance has covered most of the rural area, as of 2011 may at the end of the month, in the new rural social pension insurance number amounts to 190 million people, the 5170 people receive pensions, that is to say, China now has 51.7 million rural elderly people get the institutionalization of economic support.

Secondly, in rural areas there is a very important aspect is the elderly, "self-support." There is no statutory retirement age of farmers, farmers' labor consciousness throughout life. For many Chinese farmers, as long as they have a land, they will always work to go, unless physical conditions can't work. A large number of only child families will be more dependent elderly "self-support" old "self-support" is no choice, but the objective is also to reduce the pension burden on their children.

3) Urgent need to strengthen the spiritual solace

Only lead to the plight of the children of only child families spiritual support, realistic long-term pressure also makes it difficult at home filial children. December 28, 2012, the NPC Standing Committee adopted a new revised " Elderly Rights Law", the decision since July 1, 2013 began. Family members may not ignore the law explicitly spiritual needs of the elderly, and elderly family members living apart should always go home to visit elderly relatives employer should protect the rights of employees in accordance with national regulations.

Due to remoteness, especially in rural areas, only child families solace in the elderly mountainous area needs even more. For a family, if the child is not around, the old couple at home on long-life, but also to talk to boredom; The children of only child family families are basically out when leaving their only child, the elderly will be the lack of family comfort, lack of pleasure in later life. With support for rural local economic underdevelopment and lack of funds and other aspects of the policy, no nursing home or institutional facility Seniors Activity Centre and the like, but in the form of community care or home services used by other cities, in rural areas because of the lack of implementation of temporary the basic conditions can't be achieved. Now, the greatest difficulty is not economic reasons endowment of only child families in rural areas, but how to take good care of the elderly, to solve the spiritual needs of the elderly.

\subsection{Only Child Family Families Bear a Higher Pension Risk}

As an extremely simplified only child families this reverse pyramid's family structure, meaning that it is essentially a risk families. rural only child family parents when entering old age, most do not live together and become the year's only child family, but choose to live alone. This family structure in the elderly, living alone once become "empty nest elderly" for the elderly, the challenges facing pension will be very severe, because of as time goes by, they physical mental condition will slowly deteriorate, the demand for life, medical and psychological care pension will continue to rise, but they could not get enough support in the traditional adult children from families. Once the children of only child families accidents, the whole family is hurt, even in rural areas has become a factor in the rise and fall family decision.

Only child families are exposed to the risk of mainly family members living in the household risk and risk are two aspects of sustainable development: These two aspects are also linked, no matter what aspect of the occurrence of the accident will bring immeasurable impact. For now, at this risk families, pension risk is the most direct, most need to guard against the risks. If children are accidents, the elderly in economic terms, life care, in particular mental, will be hit, the impact on the whole family pension bring irreversible. In the only child families, for the elderly, either from or on the economic life care, children are their hope and rely on their children is an essential part of life. In the event of the same probability of risk, pension risk is higher than only child family is undoubtedly families with many children.

\subsection{Only Child Lack of Specific Policy}

Family planning as a direct product of the only child family policy is the policy to be implemented to slow population growth vehicle for its own is also a huge sacrifice. Both risk child parents raising children, they need to take risks pension, they very long time have not been appropriate care, did not enjoy the special benefits from the government or society. This is not fair for them. From this perspective, the only child families, and sacrifice should be relative and other compensation.

Now the government has started from the economic benefits of family planning families, but only limited to specific groups of individual areas, so do not be extended to only child families. Currently able to receive only child allowance in just a small part of only child families, and most of the only child were born between 1985 and 1995, meaning that their parents still can not enjoy subsidies. In addition, the sacrifices made by the only child family, the amount of government subsidies rarely, can not reflect special rewards for these families.Moreover, the state in the 
development of policies taking into account the special circumstances of useless only child family families and give preferential treatment, whether their children to school or old-age security problems are universal policy system, the lack of relevance.

\subsection{The Professional Thinking on Rural Only Child Family Family Pension}

\subsubsection{Changes in Endowment View}

Implementation of the family planning policy, making Chinese traditional family size, by many children to support their parents before evolving into a child support, pension burden adds to many. In discussing the problem of elderly dependents, Fei Xiao-tong (1983) with the " feedback mode" on the parent-child relationship between the Chinese people were too classic exposition. He pointed out that the West's "A generation raised on behalf of B, B-generation upbringing c generation" of "relay mode" is different parent-child relationship is typical of the Chinese people "a generation tending B generation, a generation B-generation maintenance; B generation tending $\mathrm{c}$ generations, propylene generation support B-generation "and" feedback mode "cultural foundation of this model is the traditional Chinese" raise children to old age "concepts. The countryside is the traditional concept retain more places, as parents, they of course need child support. But as a child, they now bear the pressure is very large, especially the first generation of only child family are married, most of them have their own next generation economy, a considerable number of families are in a "4-2-1" family structure model. In today's stressful society, people are faced with the pressure of competition for survival and development of all aspects of the house, their children to school, life, pension seemed beyond their grasp.

Modern family structure has changed, in the aging aggravating circumstances in the background, need to change the Endowment views. For the rural only child families, spiritual solace and life care lack sufficient time to achieve, but also for only child family out of work, the time to accompany the old man is impossible, therefore, in addition to the traditional way of family pension, it should emancipate the mind, the way to promote the diversification of pension, can not have the kind of "filial to parents sent to a nursing home is the" point of view. Coexistence of a variety of old-age, full use of all available resources to protect the elderly old age, is the pension issue should focus on solving the problem.

\subsubsection{Pension Risks Can not be Ignoredonly Child Family Families}

Under China has entered the aging and aging continue to highlight the background, pension risk has become a only child family family is the most serious form of risk factors. For now, the family pension is still the main way of China's rural old-age home, and social, economic, demographic and moral foundations of the traditional family pension risk prevention mechanism is breaking down, only child families have had no objective basis for the traditional Chinese family pension mode. Only child family means that only child family once they leave their parents, their parents will make a great deal of change in later life. In addition, comparison with nononly child family families with children, the children of a small number of only child families, thus creating a shortage of human resources and other related resources, will also directly affect the quality of life of their parents' old age. For such a population control who made great contributions to the elderly population, society and government should be highly concerned ,because of this part of the family would have emerged, especially for the early work is done in the areas of family planning, parentonly child family family pension problems began to appear.

\subsubsection{Should Increase the Only Child Family Compensation}

Throughout society, in addition to the only child family with other families to enjoy the same policy, it should also enjoy special discounts or subsidies. In addition to the subsidy, the government should take the initiative to reward families practicing family planning, one can increase the motivation of people to implement policies to ensure the continuity of the policy; On the other hand through the award to only child families can provide some economic help.

In addition, the social security system should reflect the special nature of the only child family, the only child of parents included in the social security system in particular, from the system to be protected in the pension and other aspects. Family planning policy is oriented interests, whether it is rewarding to support or social security, family planning and mother of all individuals to provide compensation and security measures. Institutionally depth grim situation of rural only child families are facing old age security and solutions, not just a question of the integrity of the implementation of family planning, but also a matter of overall social development and stability problems. 


\section{Conclusions}

Rural only child family pension faced many difficulties inadequate human resources, is also facing "lost independence" and many other risks. Pension risk for only child families in rural areas, the government should be safeguarded from the institutional arrangements for its pension problem. Both to make them enjoy the general elderly can enjoy pension benefits, but also to enjoy the special treatment of the family, that handle the relationship between "inclusive" and "special care" between. Government should establish a mechanism Pratt basic national policy of family planning policies and the implementation of coordinated, clear from the special status of family planning in principle, effectively promote family planning and the construction and improvement of the pension system. For the rural only child families arising from the "empty nest" families, the government can build grass-roots organizations in relevant institutions, the establishment of a nursing home for the elderly through centralized support the state, collectives and individuals tripartite financing, or promoting home care, solving life care and difficulties in terms of spiritual comfort. As a continuation of the family planning policy, we must improve the rural "lost independence for the elderly," the pension system, we must face the reality of the needs of only child families.

\section{References}

Cui Hengzhan, \& Li zonghua. (2012). Pension contents of Aging Research. Journal of Shandong Social Sciences, 29-35.

Goodstadt, Leo F. China's One-Child Family: Policy and Public Response. Journal of Population and Development Review, $1982(1), 37$.

Liang Ruiming, \& Bi Keying. (2010). The aging of the rural traditional family pension impact and Countermeasures. Journal of Labor and Social Security of the World, 14-16.

Mu Guangzong. (2004). Family child family is essentially risk. Journal of Population Study, 14.

The people's Republic of China National Bureau of statistics. The sixth national census in 2010 the main data bulletin. 